\title{
INVESTIGATION OF PROPERTIES ROSTSTIMULIRUYUSCHIH SODIUM HUMATE ON YIELD OF WHEAT
}

\author{
S.D. Fazylov, M.A. Abdikalykov, A.B. Moldybaev, A. Muchtar
}

The results of a comparative analysis of the effectiveness of methods of using sodium humate and humate urea. It is shown that they all give good yields of wheat and gain contribute to improvement of product quality.

УДК 5418:661.424

\author{
МЕТАФОСФАТ КАЛИЯ НА ОСНОВЕ ХЛОРИДА КАЛИЯ И СОЛИ ГРЭМА \\ В СИСТЕМЕ K, $\mathrm{Na} / / \mathrm{Cl}, \mathrm{PO}_{3}-\mathrm{H}_{2} \mathrm{O}$
}

\section{Б.Х. Хазиханова}

\author{
Атырауский институт нефти и газа, г. Атырау, Казахстан, aing-atr@ mail. ru
}

\begin{abstract}
Исследована растворимость в системе $\mathrm{K}, \mathrm{Na} / / \mathrm{Cl}, \mathrm{PO}_{3}-\mathrm{H}_{2} \mathrm{O}$ при $10^{\circ}, 20^{\circ}, 30^{\circ} \mathrm{C}$ и определены поля кристаллизации $\mathrm{KCl}, \mathrm{KCl}+\mathrm{KPO}_{3}, \mathrm{KPO}_{3}, \mathrm{NaCl}$, твердого раствора на основе $\mathrm{NaPO}_{3}$.

Индивидуальность выделенных твердых фаз подтверждена методами химического анализа, дериватографии, ИК спектроскопии и рентгенофазового анализа.
\end{abstract}

Фосфаты калия, в частности метафосфат калия, широко используются в производстве стекла и удобрений для сельскохозяйственных растений $/ 1 /$. Метафосфат калия получают из водного раствора хлорида калия и ортофосфорной кислоты и дегидратацией промежуточного продуктадигидрофосфата калия при $350-450^{\circ} \mathrm{C} / 2 /$. Исследование растворимости и взаимодействия хлорида калия с метафосфатом натрия в системе $\mathrm{K}, \mathrm{Na} / / \mathrm{Cl}, \mathrm{PO}_{3}-\mathrm{H}_{2} \mathrm{O}$ представляет интерес для синтеза фосфорных соединений калия. Литературные сведения по растворимости в системе $\mathrm{K}, \mathrm{Na} / / \mathrm{Cl}, \mathrm{PO}_{3}$ $\mathrm{H}_{2} \mathrm{O}$ отсутствуют.

Цель данной работы - исследование растворимости в системе $\mathrm{K}, \mathrm{Na} / / \mathrm{Cl}, \mathrm{PO}_{3}-\mathrm{H}_{2} \mathrm{O}$ при $10^{\circ}$, $20^{\circ}, 30^{\circ} \mathrm{C}$. Для работы использованы $\mathrm{KPO}_{3}, \mathrm{NaPO}_{3}$ (соль Грэма марки х.ч.) и $\mathrm{KCl}, \mathrm{NaCl}$ марки х.ч. Метафосфат натрия (соль Грэма) синтезирует путем термообработки дигидрофосфата натрия /2/. Мною /3/ впервые разработан способ получения метафосфата натрия (соли Грэма) путем термообработки ацетата натрия и метафосфорной кислоты в массовом соотношении $(1,01-1,04): 1$ до $800^{\circ} \mathrm{C}$. Метафосфат калия синтезирован взаимодействием хлорида калия с солью Грэма на основе системы K, $\mathrm{Na} / / \mathrm{Cl}, \mathrm{PO}_{3}-\mathrm{H}_{2} \mathrm{O}$. Метафосфат калия - $\mathrm{KPO}_{3}$ и метафосфат натрия - $\mathrm{NaPO}_{3}$ существуют в различных модификациях. Физико - химические свойства зависят от условий их синтеза. $\mathrm{NaPO}_{3}$ существует в трех модификациях: Мадрелла, Курроля, Грэма.

Соль Грэма - водорастворимый стеклофосфат. Стеклофосфат образуется при нагревании $\mathrm{NaH}_{2} \mathrm{PO}_{4}$ до $620^{\circ}$ или $\mathrm{NaH}_{2} \mathrm{PO}_{4} \cdot 2 \mathrm{H}_{2} \mathrm{O}$ до $800^{\circ}$ и быстром охлаждении $/ 2 /$.

Соль Мадрелла незначительно растворима в воде и в растворах солей при комнатной температуре. Соль Мадрелла получают дегидратацией $\mathrm{NaH}_{2} \mathrm{PO}_{4} \cdot 2 \mathrm{H}_{2} \mathrm{O}$ при температурах ниже 475 $500^{\circ}$. Полученный $\mathrm{NaPO}_{3}$ представляет собой мелкие кристаллы /2, 4/.

Соль Курроля незначительна растворима в воде, но легко растворима в растворах солей, содержащих катионы других металлов. Соль Курроля легче всего образуется при выдерживании $\mathrm{NaH}_{2} \mathrm{PO}_{4} \cdot 2 \mathrm{H}_{2} \mathrm{O}$ при $550^{\circ}$. Выделенный $\mathrm{NaPO}_{3}$ имеет волокнистую структуру, похожую на структуру асбеста $/ 2,4 /$.

Литературные данные по растворимости различных модификации $\mathrm{NaPO}_{3}, \mathrm{KPO}_{3}$ в системах $\mathrm{NaPO}_{3}-\mathrm{H}_{2} \mathrm{O}$ и $\mathrm{KPO}_{3}-\mathrm{H}_{2} \mathrm{O}$ отсутствуют.

Изучение растворимости проведено в изотермических условиях (при 10, $20^{\circ}, 30^{\circ}$ ). Составными частями растворимости системы $\mathrm{K}, \mathrm{Na} / / \mathrm{Cl}, \mathrm{PO}_{3}-\mathrm{H}_{2} \mathrm{O}$ являются ранее не изученные системы $\mathrm{KCl}-\mathrm{KPO}_{3}-\mathrm{H}_{2} \mathrm{O}$, $\mathrm{KPO}_{3}-\mathrm{NaPO}_{3}-\mathrm{H}_{2} \mathrm{O}, \mathrm{NaCl}-\mathrm{NaPO}_{3}-\mathrm{H}_{2} \mathrm{O}$, за исключением системы KCl-NaCl$\mathrm{H}_{2} \mathrm{O}$, описанной в справочнике /5/. Равновесие в системе устанавливалось через 10-12 ч. Содержание хлора определено объемным методом /6, с. 84/, калия-гравиметрическим /6, с.120/, натриягравиметрическим /6, с. 140/ и фосфора-объемным /7/. Выделенные твердые фазы исследованы термографическими, ИК спектроскопическими и рентгенографическими методами анализа. Термографические исследования проведены на дериватографе фирмы МОМ (Будапешт), ИК спектры 
образцов были сняты в таблетках с KBr на спектрофотометре UR-20 в интервале частот 450-4000 см ${ }^{-1}$. Рентгенофазовый анализ образцов осуществлены на дифрактометре ДРОН-3 с использованием $\mathrm{Cu}_{\mathrm{K} \alpha}-$ излучения. Экспериментальные данные приведены на рис. 1-3.

Система $\mathrm{NaCl}-\mathrm{NaPO}_{3}-\mathrm{H}_{2} \mathrm{O}$ при $10^{\circ}, 20^{\circ}, 30^{\circ}$ состоит из двух ветвей кристаллизации: $\mathrm{NaCl}$ и твердого раствора на основе $\mathrm{NaPO}_{3}$.

Система $\mathrm{KPO}_{3}-\mathrm{NaPO}_{3}-\mathrm{H}_{2} \mathrm{O}$ при $10^{\circ}, 20^{\circ}, 30^{\circ}$ имеет две ветви кристаллизации: $\mathrm{KPO}_{3}$ и твердый раствор на основе $\mathrm{NaPO}_{3}$, система относится простому эвтоническому типу.

Система $\mathrm{KCl}-\mathrm{KPO}_{3}-\mathrm{H}_{2} \mathrm{O}$ при $10^{\circ}, 20^{\circ}, 30^{\circ}$ состоит из двух ветвей кристаллизации $\mathrm{KPO}_{3}$ и $\mathrm{KCl}$ и относится простому эвтоническому типу.

Система $\mathrm{KCl}-\mathrm{NaCl}-\mathrm{H}_{2} \mathrm{O}$ состоит из двух ветвей кристаллизации $\mathrm{KCl}$ и $\mathrm{NaCl}$.

На рис.1 приведены диаграммы растворимости системы $\mathrm{K}, \mathrm{Na} / / \mathrm{Cl}, \mathrm{PO}_{3}-\mathrm{H}_{2} \mathrm{O}$ при $10^{\circ}, 20^{\circ}, 30^{\circ}$, изображенные по Йенеке. Состав точек на диаграммах выражен в ионных процентах. Для всех точек системы сделан пересчет на солевой состав по принципу преимущественного связывания ионов в менее растворимые соли.

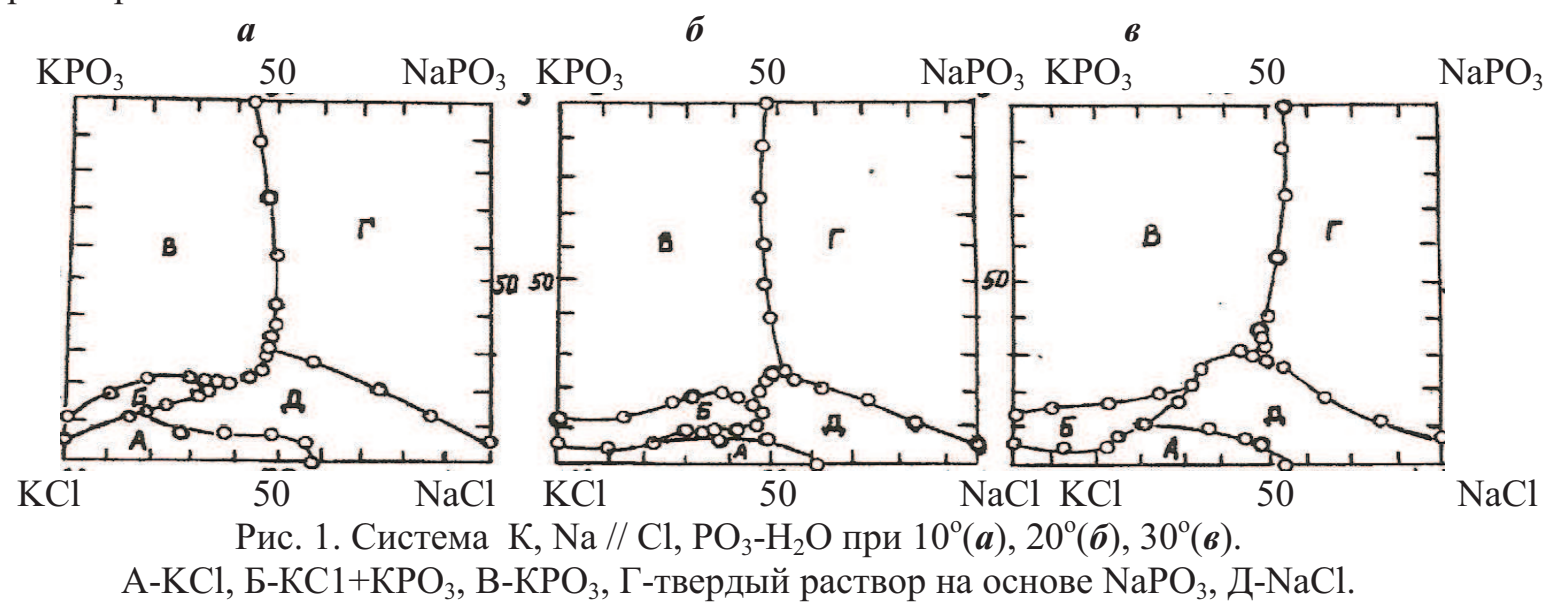

$\mathrm{B}$ системе $\mathrm{K}, \mathrm{Na} / / \mathrm{Cl}, \mathrm{PO}_{3}-\mathrm{H}_{2} \mathrm{O}$ ограничены пять полей кристаллизации: $\mathrm{KCl}, \mathrm{KCl}+\mathrm{KPO}_{3}$, $\mathrm{KPO}_{3}, \mathrm{NaCl}$ и твердый раствор на основе $\mathrm{NaPO}_{3}$. Наибольшую по величине площадь на диаграмме занимает поле кристаллизации $\mathrm{KPO}_{3}$ при $30^{\circ}$, затем при $20^{\circ}$, наименьшее поле $\mathrm{KPO}_{3}$-при $10^{\circ} \mathrm{C}$, затемполе кристаллизации твердого раствора на основе $\mathrm{NaPO}_{3}$, поля кристаллизации $\mathrm{NaCl}, \mathrm{KCl}+\mathrm{KPO}_{3}, \mathrm{KCl}$ невелики.

По занимаемой площади поля кристаллизации $\mathrm{KPO}_{3}$ можно заключить, что возможно разделить хлорид натрия и метафосфат калия при конверсионном получении последнего.

ИК спектры продуктов взаимодействия приведены на рис.2. В ИК спектре имеются полосы поглощения в области 480, 530, 740, 870, 900, 1030, 1090, $1150 \mathrm{~cm}^{-1}$, соответствующие метафосфату калия. В отличие от спектра $\mathrm{NaPO}_{3}$ (соли Грэма) в спектре $\mathrm{KPO}_{3}$ появляются размытые полосы поглощения в области 900, 1030, $1150 \mathrm{~cm}^{-1}$ (рис.2).

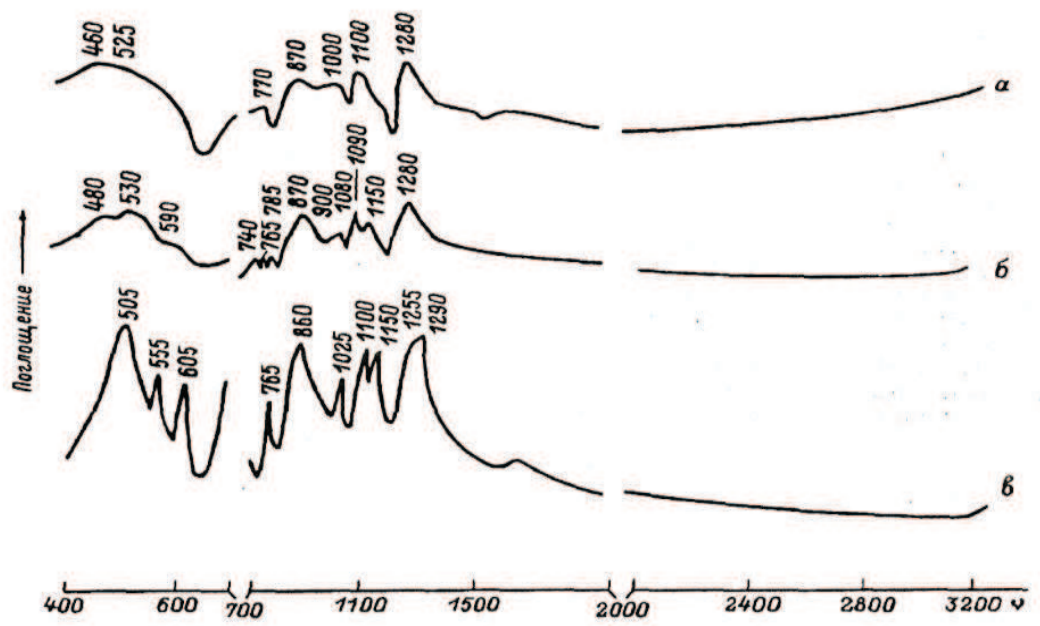

Рис.2. ИК спектры поглощения. v-частота $\left(\mathrm{cm}^{-1}\right) . a-\mathrm{NaPO}_{3}$ (соль Грэма); б-КРО из системы $\mathrm{K}, \mathrm{Na} / / \mathrm{Cl}, \mathrm{PO}_{3}-\mathrm{H}_{2} \mathrm{O}$ при $10^{\circ}, 20^{\circ}, 30^{\circ} ; 6$ - $\mathrm{KPO}_{3}$, полученный при термообработке $\mathrm{KH}_{2} \mathrm{PO}_{4}$ (при $\left.342^{\circ}\right)$. 
На кривой ДТА $\mathrm{KPO}_{3}$ имеются экзотермические эффекты при 110, 195, 253, 470, 610, которые отвечают превращению из одной формы модификации в другую. Эндотермический эффект при $253^{\circ}$ отвечает плавлению начальной модификационной формы $\mathrm{KPO}_{3}$. При температуре $800^{\circ} \mathrm{C}$ образуется жидкий фосфат, который при охлаждении переходит в стеклофосфат.

На кривой ДТА $\mathrm{KPO}_{3}$ наблюдаются эндотермические эффекты, отвечающие переходу $\mathrm{KPO}_{3}$ в другую форму модификации с одновременным удалением влаги при 253 и $470^{\circ}$ от 2 до 4\% соответственно.

Результаты рентгенографического исследования $\mathrm{KPO}_{3}$ приведены на рис.3. На рентгенограмме $\mathrm{KPO}_{3}$ по сравнению с солью Грэма найдены полосы $(\AA)$ : 2. 22, 2. 74, 2. 91, 3. 14, 3. 72. Полученный данные соответствуют новой модификации высокополимерного $\mathrm{KPO}_{3}$ (рис.3, в) по сравнению с модификацией $\mathrm{KPO}_{3}$, полученной при термообработке $\mathrm{KH}_{2} \mathrm{PO}_{4}$ при $342^{\circ} \mathrm{C}$ (рис.3, г).

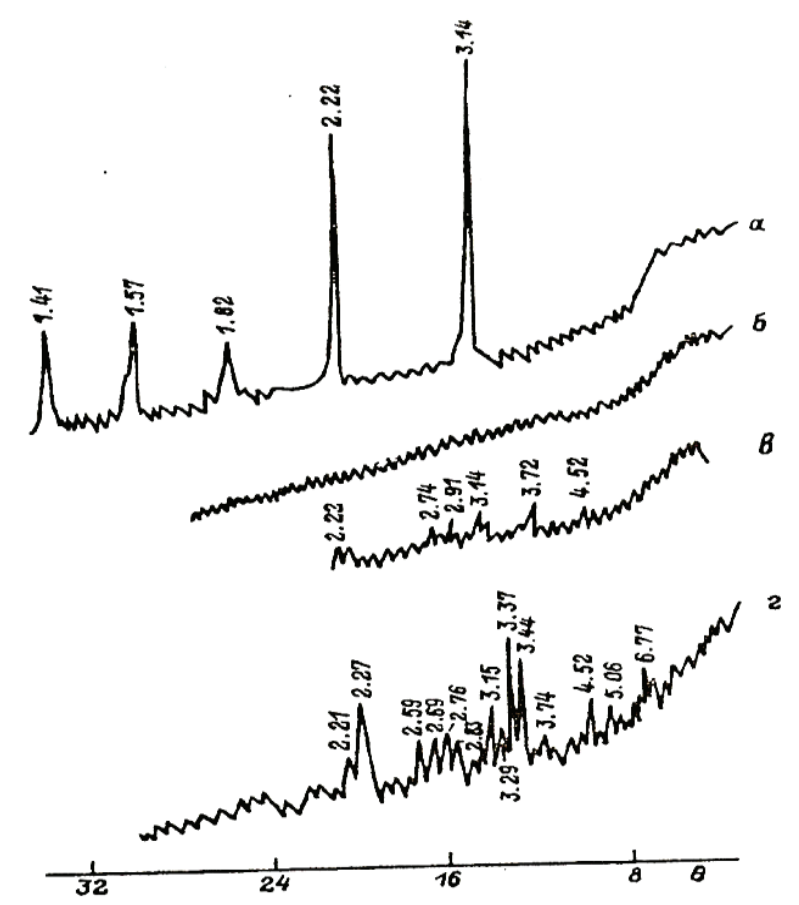

Рис.3. Рентгенограммы КС1 (a), $\mathrm{NaPO}_{3}$ (соль Грэма) (б), КРО $\mathrm{PO}_{3}-\mathrm{H}_{2} \mathrm{O}$ при $10^{\circ}, 20^{\circ}, 30^{\circ}$ (b), $\mathrm{KPO}_{3}$, полученного при термообработке $\mathrm{KH}_{2} \mathrm{PO}_{4}$ при $342^{\circ}$ (2). $\theta$ - угол отражения (град).

Таким образом результаты исследования показывают возможность выделения метафосфата калия путем взаимодействия хлорида калия с метафосфатом натрия (солью Грэма) из систем, содержащих $\mathrm{K}, \mathrm{Na} / / \mathrm{Cl}, \mathrm{PO}_{3}-\mathrm{H}_{2} \mathrm{O}$ при невысокой температуре $\left(10^{\circ}, 20^{\circ}, 30^{\circ}\right)$ с выходом $90,71-99,88 \%$ и содержанием основного продукта $100 \%$. Реакция образования $\mathrm{KPO}_{3}$ стабильна, по сравнении с известными синтеза $\mathrm{KPO}_{3} / 1,8-12 /$ ускоряется время образования метафосфата калия в твердой фазе в 5,5-8,7 раза и уменьшается температура образования в 2-27 раз, позволяет получить $\mathrm{KPO}_{3}$ в одну стадию против двух стадийных.

\section{Литература}

1. Кочетков В.Н. Фосфорсодержащие удобрения: Справочник. М.: Химия, 1982. 400 с.

2. Ван Везер Дж.Р. Фосфор и его соединения/ Пер. под ред. А.И.Шерешковского. М.: ИЛ, 1962.687 с.

3. А.С. 1740315 (СССР). Способ получения метафосфата натрия (соли Грэма).// Б.Х.Хазиханова-Опубл. в Б.И., 1992. №22. Пат.888 (РК). Опубл. в О.Б., 1994. №2.

4. Корбридж Д. Фосфор. Основы химии, биохимии и технологии: Пер. с англ. М.: Мир, 1982. 680 с.

5. Справочник по растворимости. Т.3. Кн. 2-я. Л.: Наука, 1969. С.136.

6. Морачевский Ю.В., Петрова Е.М. Методы анализа рассолов и солей. М.: Л.: Химия, 1965. 403 с.

7. Книпович Ю.Н., Морачевский Ю.Б. Анализ минерального сырья. Л.: Госхимиздат, 1959. 1055 с. 
8. Гирич Т.Е., Гулямов Ю.М., Ганц С.Н.: Баркова В.В. Растворимость в системе $\mathrm{NaH}_{2} \mathrm{PO}_{4}+\mathrm{KCl} \leftrightarrow \mathrm{KH}_{2} \mathrm{PO}_{4}+\mathrm{NaCl}-\mathrm{H}_{2} \mathrm{O}$ при температурах кипения насыщенных растворов.// Журн.неорган.химии.1981-T.26.-№9.-С.2567-2569.

9. Халлиева Ш.Д. Растворимость в тройных водно-солевых системах $\mathrm{KH}_{2} \mathrm{PO}_{4}-\mathrm{NaH}_{2} \mathrm{PO}_{4}-\mathrm{H}_{2} \mathrm{O}, \mathrm{NaH}_{2} \mathrm{PO}_{4}$ $\mathrm{NaCl}-\mathrm{H}_{2} \mathrm{O}$ и $\mathrm{KH}_{2} \mathrm{PO}_{4}-\mathrm{KCl}-\mathrm{H}_{2} \mathrm{O}$ при $40^{\circ} \mathrm{C}$. Четверная водно-солевая система $\left(\mathrm{Na}^{+}, \mathrm{K}^{+}\right),\left(\mathrm{Cl}^{-}, \mathrm{H}_{2} \mathrm{PO}_{4}^{-}\right) \mathrm{H}_{2} \mathrm{O}$ при $40^{\circ}$ C.// Изв. АН Туркм.ССР. Сер.физ.техн.хим. и геолог.наук-1977.-№3-С.125-127.

10. Pat. 3650684 (USA). Manufacture of potassium metaphosphate.//Watson Jumesw.-Опубл. В РЖХим. 1973, 3Л72П.

11. Pat. 2437748 (FRG). Verfahren zur Herfahren zur Hewitilung von Kalium phosphat brwpolyphosphat.//Worttunyton Ralph Eric, Somers Thomas Noel.-Опубл. в РЖХим. 1976, 22Л133П.

12. Pat. 1388145 (Eng.) Potassium phosphates forilistrs.// Thompson William Henry, Worthington Ralph.Опубл. в РЖХим., 1976, 4Л167П.

\title{
K, Na // Cl, РО $-\mathrm{H}_{2} \mathrm{O}$ ЖҮЙЕСІНДЕГІ КАЛИЙ ХЛОРИДІ МЕН ГРЭМ ТҰЗЫ НЕГІЗІНДЕГІ КАЛИЙ МЕТАФОСФАТЫ
}

\section{Б.Х. Хазиханова}

$\mathrm{K}, \mathrm{Na} / / \mathrm{Cl}, \mathrm{PO}_{3}-\mathrm{H}_{2} \mathrm{O}$ жүйесіндегі ерігіштігі $10^{\circ}, 20^{\circ}, 30^{\circ} \mathrm{C}$ зеріттелді және $\mathrm{KCl}, \mathrm{KCl}+\mathrm{KPO}_{3}, \mathrm{KPO}_{3}, \mathrm{NaCl}$ және $\mathrm{NaPO}_{3}$ негізіндегі қุатты ерітінділердің кристалдану аумақтары анықталды. Бөліп алынван к̧атты фазаларды химиялық анықтау ддісімен, дериватографиялық, ИК спектроскопия жсне рентгенфазалық ддістермен тазалывы бекітілді.

\section{POTASSIUM METAPHOSPHATE ON A BASIS POTASSIUM CHLORIDE AND GRAM SALT IN SYSTEM K, Na // Cl, $\mathrm{PO}_{3}-\mathrm{H}_{2} \mathrm{O}$}

\section{B.Kh. Khazikhanova}

The solubility in system $\mathrm{K}, \mathrm{Na} / / \mathrm{Cl}, \mathrm{PO}_{3}-\mathrm{H}_{2} \mathrm{O}$ is investigated at $10^{\circ}, 20^{\circ}, 30^{\circ} \mathrm{C}$ and the fields crystallization $\mathrm{KCl}, \mathrm{KCl}+\mathrm{KPO}_{3}, \mathrm{KPO}_{3}, \mathrm{NaCl}$, firm solution on a basis $\mathrm{NaPO}_{3}$ are determined. The individuality of the selected firm phases is confirmed by methods of the chemical analysis, derivatography, IR spectroscopy and X-ray of the analysis.

УДК 665.664.2:661.183.6

\section{КАТАЛИТИЧЕСКИЙ КРЕКИНГ КЕРОСИНО-ГАЗОЙЛЕВЫХ ФРАКЦИЙ СМЕСИ 70\% ЭМБИНСКИХ И ЗО\% МАНГЫШЛАКСКИХ НЕФТЕЙ НА ЦЕОЛИТСОДЕРЖАЩИХ КАТАЛИЗАТОРАХ}

\author{
А.М. Шахманова, Т.А. Ягудеев, Н.У. Алиев \\ Казахский национальный технический университет им. К.И. Сатпаева, г. Алматы, \\ Республика Казахстан, asshakhmanova@yandex.ru
}

\begin{abstract}
Показано, что каталитическое превращение КГФ смеси 70\% мангышлакских и 30\% эмбинских нефтей на цеолитсодержащем катализаторе АШНЦ-3 при низких температурах с увеличением объемной скорости до 0,75 час ${ }^{-1}$ приводит к незначительному росту мотобензина (при $375^{\circ} \mathrm{C} \mathrm{на} \mathrm{0,6 \% ,} \mathrm{при} \mathrm{400}{ }^{\circ}$ С на 3,25\%), однако дальнейшее повышение до 1,0 час ${ }^{-1}$ ведет к значительному его снижению, максимальный выход бензина достигается при температуре $425^{\circ}$ С и объемной скорости подачи сырья 0,75 час -1 - 57,16\%. Увеличение объемной скорости подачи сырья на ЦЕОКАР-2 при постоянной температуре также приводит к снижению глубины превращуения, росту содержания легких каталитических газойлей, снижению газообразования и уменьшению выхода кокса.
\end{abstract}

Введение методом катионного обмена в цеолитную структуру редкоземельных металлов приводит не только к увеличению активности катализаторов по сравнению с другими катионными формами его, но и увеличивает термическую и гидролитическую стабильность катализатора / 1, 2/

Наиболее активными показали себя смешанные кислые металлические формы цеолита «Х»и «У», где часть щелочных катионов замещена поливалентными катионами (Ca, $\mathrm{Mg}, \mathrm{mn}, \mathrm{P} 3 \mathrm{M}$ и др.), a другая часть - катионом аммония, который впоследствии разрушался при температурных обработках, образуя декатионированные или кислые участки. Такие формы являются более активными, чем только катионные (металлические). Кислые металлические формы цеолитов «Х» и «У» дают в 2 раза 